patient, who was a stout, plethoric man, died on the fourth day of his illness, June 3rd. Mrs. D- nursed her husband during his brief illness. After the corpse was placed in the coffin, and the lid screwed down, there must have been rapid decomposition of the body, attended by considerable evolution of gas, for the coffin burst, and there escaped a large quantity of liquid which had a most disagreeable and olfensive odour. For a day or two all the inmates of the house felt ill. On June 6 th-i.e., three days after the death of her husband-Mrs. D-had a severe rigor, and soon after this the physical signs of pneumonia gradually presented themselves. When I saw her on June 13th there was double pueumonia with well-marked physical signs, rusty sputa, \&c. Her temperature was $103.8^{\circ}$; pulse 120 ; respiration 40 ; tongue dry. She was more or less delirious, flushed in the face, perspiring freely, and passing her urine involuntarily. On the following day whe seemed rather better; her breathing was easier; she was less delirious, and her temperature, which at midnight had risen to $104^{\circ}$, had fallen to $103^{\circ}$. Daring the course of the day a very offensive diarrhoea occurred; this continued. Towards evering she was cyanosed; her respiration was difficult-44,-pulse 140, tongue very dry, and her pupils were slightly dilated. The case was regarded as one of severe blood poisoning rather than of pure pneumonia, and was treated accordingly. On June 15 th she was in a heavy somnolent condition, the pupils contracted, face dusky and pinched, pulse 140, respiration 52, and diarrhoea continuing. In the evening she died. During our attendance upon Mrs. D_— we found one of her sons, aged twenty, also suffering from pneumonia, with high fever. Until June 9th he had been quite well, when, on going to business, he was seized with a severe rigor, obliging him to return home, and take to bed. On the following day he developed cough; on the 1lth he began to expectorate on the 12 th the expectoration was rusty; temperature $103^{\circ}$. When I saw him on June 13 th there was dulness over the base of the left lung, with coarse, dry, tubular respiration. The heart was healthy, pupils slightly dilated, pulse 112, cespiration 28 , and temperature $103 \cdot 2^{\circ}$. During the night he had a profuse sweating (?critical) From this date he began to mend - temperature, pulse, and respiration gradually declining to the normal. Almost contemporameously with the profuse sweating a mild diarrhoea appeared, which continued for three days, being gradually checked by tannic acid. This patient made a good and permanent recovery. During the early part of his convalescence the râles persisted in the leftlung. The area of splenic dulness, it may be mentioned, was during his illness slightly increased.

Shortly afterwards I saw in a neighbouring town on Tyneside three cases of pneumonia. The patients lived witbin a tew yards from each other. In them the illness showed itself suddenly. The rigor was severe, as were also all the symptoms from the first. The pneumonia was double. Two of the patients were teetotallers. The disease ran rapidly to its termination, death occurring on the sixth and seventh days. One of these patients, a man aged fortyone, had a rigor on July $5 \mathrm{th}$; he died on the 12 th. The case had been going on apparently satisfactorily, when all at once, and without any explanation, the pulse rose to 240 per minute. Delirium and restlessness supervened, so that the patient could not be kept in bed. in this hopeless condition I saw him, with extremely rapid pulse and breathing, and deeply cyanosed. He died two hours after onr visit. In one of the other cases-two doors away from the last-the symptoms of a less severe pneumonia were followed by those of toxæmia. The symptoms were those of meningitis, but without headache and vomiting ; there were great sleeplessness and picking of the bedclothes. Large doses of sulpho-carbolate of soda were given, and one draught of tincture of hyoscyamus soon quieted him. On the following day he showed signs of amendment, and in a few days after this he recovered. Earlier on in the year, in a case which I saw with Dr. Drummond of South Shields, the patient had quite recovered from a severe attack of pneumonia when suddenly his temperature rose, a right-sided hemiplegia developed, and he died comatose, the paralysis in this case being evidently due to the plugging of a cerebral artery by an embolon of a septic character. I mention this latter case not as an illustration of infective pneumonia, but to show that even after recovery from pneumonia has been complete the individual is not tree from the risk of septic infection. Our patient had been perfectly well for at least seven or eight days, when, after sitting up for the greater part of a day working at his ledger, he had a rigor, followed by a rise of temperature, and it was noticed that his speech was slightly affected. Next day the aphasia was complete, and there was paralysis of the right arm. Two days subsequently be had a fit, and after this the right leg was seen to be paralysed. He died shortly afterwards comatose. The only explanation we can offer of this infection is that the man, who was a poultry salesman, lived above his shop, and during convalescence he moved into a room immediately above it. Sitting here all day breathing an atmosphere tainted by emanations from below, there had been doubtlessly carried into his lungs-not yet thoroughly rid of pneumonic materialorganisms of a septic character.

Newcastle-upon-Tyne.

\section{TWO CASES OF GASTRO-ENTEROSTOMY.}

By GEORGE T. BEATSON, B.A. Cantab., M.D. Edin., ASSISTANT SURGEON, WESTERN INFIRMARY, GLASGOW.

I HAVE preferred to publish these two cases together, as they were under observation almost simultaneously, and had, as the sequel will show, some bearing one upon the other.

The first case was that of $\mathrm{P}-\mathrm{V}-$, a miner, aged forty-five, who was a patient under Professor Gairdner in the Western Infirmary, and who was traneferred to Sir George Macleod's surgical wards for operative treatment. Owing to Sir George Macleod's prolonged attendance in London at the Medical Council, and looking to the somewhat urgent condition of the case, it was deemed advisable that $I$ should deal with it before his return. According to the statement of the patient on his first admission to Professor Gairdner's wards on April 24th of the present year, his illness was of twelve months' duration, and had commenced with pain in the stomach and other signs of indigestion. The pain was almost constantly present, but was always worse afcer food, when it would become severe for some hours. It never caused vomiting, though on one or two occasions he had himself induced sickness with the view of obtaining relief. He began to lose flesh, and in the early part of last March he noticed a lump in his abdomen in the region of the seat of pain. For a short time before his admission to the infirmary he thought the pain had been less, and he did not consider that there had been any great increase in the tumour since it was first observed. His condition on admission in April was as follows: He was emaciated to a considerable degree and had a rather sallow complexion. There was no doubt as to the existence in the right hypochondriac region of a tumour of an irregular and oval shape, somewhat like a large turkey's egg, one side and end of which seemed to rest on the lower surface of the liver. On the whole, the tumour had considerable mobility, and in particular it could be moved from side to side, showing that it was not firmly attached to the liver, although not separated from it by percussion with absolute distinctness. On inspiration it descended to a perceptible extent with the diaphragm, but the amount varied, and sometimes it was not quite easily appreciable. The longest diameter of the tumour, taken in the line of the hypochondrium, was four inches as against three across. On manipulation there appeared to be only one mass with a few inequalities on its surface. No history of any gastric or intestinal hæmorrhage could be made out. In fact, the bowels were apparently very little affected by the presence of the tumour, and the patient was otherwise healthy as regards lungs, heart, and kidneys. No hereditary tendency to cancerous disease was elicited. During the patient's residence in hospital it was established from the distinct succussion and other symptoms present that there was a moderate degree of dilatation of the stomach, and the diagnosis arrived at by Professor Gairdner was that the tumour was connected with the pyloric end of the stomach and was probably malignant, but he conld not satisfy himself that there was complete occlusion of the orifice. Examination of the vomited matters and of the contents of the stomach, when that organ was washed out, was purely negative, and never revealed any sarcinæ. At this time the question of surgical interference was raised, but the patient was rather averse to any operative measures, and he left the hospital on May 9 th after a residence of about a fortnight. 
On May 26th he was readmitted at his own request, as he was anxious anything should be done that would give him relief, his pain and inability to take food having increased. He had emaciated very considerably in the interval, and was now very much weaker. The tumour also seemed larger, but it was thought that this might be due to the greater wasting and thinning of the abdominal parietes, thus rendering the deep parts more accessible to palpation. In other respects the tumour had not altered its characters, and was still situated in the right hypochondrium, midway between the umbilicus and the ribs. It was at this time that I was asked to see the case with the view of surgical interference. My own examination only served to confirm me in the correctness of the diagnosis of pyloric tumour, but I felt that it was useless, owing to the patient's weak and emaciated condition, to think of performing any excision of the growth. I did, however, consider that it was justifiable to open the abdomen, and, if the conditions were found favourable, to perform gastro-enterostomy. The nature of the operation with its risks were put before the patient, and, as he wished it to be performed, I operated on the morning of Saturday, May 31st. The only preparatory treatment adopted was the washing out of the stomach on the previous evening and on the morning of the operation. The abdomen was opened by an incision in the linea alba, reaching from a little below the ensiform cartilage to the umbilicus. Examination of the tumour showed it to be connected with the pylorus, and that the other conditions seemed favourable for gastro-enterostomy. To allow of this being done, it was found necessary to extend the incision downwards, for the stomach was so dilated that there was a difficulty in getting hold of a suitable coil of small intestine. No prolonged search was made to obtain a portion near the duodenum. I selected a loop that seemed to apply itself easily to the stomach. As the omentum was not large, I carried the loop of bowel round its edge, and joined it to the anterior wall of the stomach at a point well interior to the growth. The junction of the stomach and bowel was effected by a pair of Senn's bone plates threaded with chromic gut, as recently suggested by Mr. Jessett, and the portion of intestine opened into was temporarily constricted during the introduction of the plate by two of Makin's clamps. No difficulty was experienced in connecting the stomach and bowels by the plates, and when the threads were tied the parts were in very close approximation. Two Lembert sutures of support were inserted at each extremity of the plates to prevent any tilting of them. The parts were then returned into the abdomen, and the abdominal wound closed. The operation lasted about half an hour, and was very well borne by the patient.

The subsequent history of the case was as follows. Reliance was placed entirely on rectal feeding by peptonised suppositories, and nothing was given by the mouth beyond snill pieces of ice to allay thirst. There was no sickness, and patient expressed himself as feeling comfortable and free from pain. The pulse and temperature kept within fair limits, and the strength seemed fairly maintained until early on Tuesday morning, when he had a weak attack and the temperature rose to $104^{\circ}$. When I saw him about $10 \mathrm{~A}$. M. on that day $\mathbf{I}$ found him much weaker and apparently dying. Stimulants and peptonised beef-tea were given by the mouth but he gradually sank and died, apparently from asthenia, between one and two o'clock in the afternoon of that day.

No complete post-mortem examination of the body could be obtained, but permission was given to examine the condition of the parts at the seat of operation. This was done by Dr. Henry Rutherfurd, to whom I am indebted for a very full report, of which the following are the leading points. The artificial opening in the stomach had been made five inches and a half from the pylorus, measured in a straight line, ana quite close to the greater curvature. All round this spot there was a thick layer of fibrinous matter, and the serous surfaces brought into contact were glued together with some firmness, but the adhesion was evidently not to any extent organic, for the manipulations necessary to remove the stomach from the abdomen caused some separation of them at the pyloric end, and the stitch of support there had cut itself out very easily. The knot of the uppermost lateral threads was plainly visible, owing to the serous surfaces having fallen apart, probably on losing the support of the bone plates. These latter had been greatly acted on by the digestive fluids, being reduced to the thickness of the thumb nail and broken up into pieces both in the stomach and bowel. It seemed as if only the central parts unaffected by the decalcifying process bacd survived. The point of the jejunum united to the stomach was about seven feet from the lower end of the duodenum. The artificial orifice admitted the forefinger freely. The tumour occupied the posterior wall of the stomach for the last three inches, and formed a sessile rather sharply defined mass nearly three inches in diameter, like a small orange, flattened on the surface from ulceration. Just before the pylorus there was a ring of polypoid or villous outgrowths from the mucous membrane, quite surrounding the lumen of the vircus; but the pylorus itself easily admitted a finger. Microscopically the tumour was of the scirrhus variety of malignant disease. On examining the parts myself I was struck by the amount of firm union that had taken place between the stomach and bowel, and I regretted I had not given nourisbment earlier by the mouth. I do not know that it would have averted the fatal issue, as the malignant disease was very extensive and the patient's strength very far gone; but I felt that it would have been quite justifiable to have done so. In other respects the steps of the operation seemed to be satisfactory; and as I had arranged to operate that afternoon on another case of pyloric tumour in private, I decided to adopt the same mode of procedure as to the use of the bone plates and othe1 matters of detail. I also resolved that in this second case the patient being emaciated and extremely feeble, I would give nourishment by the mouth from an early period.

The second case was that of Mre. R-, aged fifty-eight, whose present illness dated from November of last year. It commenced with a distressing water-brash, which was always preceded by an uncomfortable dragging pain in the stomach, relieved, however, when the fluid came away by the mouth. This condition of matters continued, and was accompanied by decided loss of health. At the latter end of March of this year vomiting began as a symptom. At first it occurred every two or three days and then every day, while on a few occasions it happened twice daily. Its characteristic was that it would sometimes come on very quickly and take place without any great effort. The vomitel matters consisted of a brownish liquid with lumps of curdled milk in it, if that fluid had been taken. The bowels became very confined, and acted only in response to injections, the stools being always very scanty. Pain was never a very marked symptom. The patient suffered from a feeling of uneasiness in the stomach, with an inclination to vomit, though often nothing came away. Up to this time she had not sought medical advice, but contented herself with being careful as to her diet, which was largely composed of milk, soups, and jellies. It was not until the middle of April that she consulted two medical men, one of whom told her she had a growth in connexion with the bowels, and advised her to get other advice in reference to it. For some time she was so weakened by vomiting that she could not leave home, but eventually an improve. ment showed itself, and she came to some friends in Glasgow, who took my opinion on her case. When first saw her at the end of May she was markedly emaciated, and was still sufferiug from the weakness following the exertion of her journey from the south. She could take but very little food, and felt a return of the inclination to vomit. Her pulse was small and feeble. In. spection of the abdomen revealed the presence of a sausageshaped tumour lying somewhat obliquely but almost paralle? to the middle line of the body, and occupying partly the right lumbar, umbilical, and hypogastric regions. It was situated outside of and rather below the umbilicus, its centre being about that point. On manipulation it felt very dense, but could be freely moved from side to side and up. wards towards the epigastrium. In length it measured about three inches and a half, and was separated from the liver by an area of clear percussion. It was not affected by the respiratory movements, which, however, were very shallow and rather feeble. Owing to the very thin state of the abdominal walls and the collapsed empty condition of the intestines. the tumour could be freely handled, and it could be grasped by the fingers in its entirety and lifted up. No pain was complained of during manipulation. The first impression 1 formed of the tumour was strengthened by subsequent examination of it, and the opinion I came to was that the patient was suffering from malignant disease of the pylorus. My reasons for thinking this to be the nature of the case were the symptoms already given above and thecoexistence of evidence of dilatation of the stomach, this last condition, to my mind, accounting also for the somewhat unusual position of the 
growth, which was lower down and more to the outer side than I had previously seen. Although there was no family history of malignant disease in the family, I considered that the rapidity of the growth and its denseness pointed to that being its nature. Assuming that the tumour was pyloric, the next question was as to what extent it had invaded the orifice. The great dilatation of the stomach, the empty state of the bowels, and the character of the vomiting, allindicated to my mind that there was almost complete occlusion of the opening. The advice, accordingly, I gave as to treatment was that the abdomen should be opened, the exact nature of the tumour ascertained, and, if the view taken of the case proved to be correct, that gastro-enterostomy should be done. To this proposal the patient and her friends consented, and on June 4th I operated, with the kind assistance of Drs. Renton, Wilson, and Bryce, and Dr. Connal of Peebles. In this case there was no previous washing out of the stomach. My reason for omitting this preliminary was that the patient had never undergone it before, and in her weak and nervous state I felt that it would be anything but a good preparation for the operation. What was decided on instead was, after the opening into the stomach had been made, to syphon out its contents with a soft rubber tube, and then to wash out the viscus with boric lotion. This was done, and it answered very well, though it increased somewhat the length of the operation. The contents of the stomach proved to be of a black, almost tarry, fluid of this consistence. The anrsthetic used was ether. When the abdomen was opened the diagnosis of a pyloric tumour was fully confirmed, but the growth was of such dimensions that the patient's weak and emaciated condition quite precluded any attempt to remove it. Gastroenterostomy was accordingly done by means of decalcified bone plates, the steps of the procedure being the same as in the previous case, with the exception of the cleansing out of the stomach (in the way alrearly described) and the threading of the plates with fine Chinese silk instead of chromic gut. This latter point of difference was not due to any want of confidence in the chromic gut, but the plates had only arrived from London on the morning of the operation, and I had not time to change the silk with which they were already threaded to chromic gut. The operation lasted about three-quarters of an hour, and the patient was put back to bed with her general condition fairly good.

As to the after progress and after treatment of the case, I need not go into minute details. The patient vomited once on the evening of the operation, but not again. As soon as she came out of the aniesthetic and could swallow, thirty drops of brandy were given every hour by the mouth. In addition, zyminised rectal suppositories were employed every four hours. Next morning feeding by the mouth was commenced, milk and lime water and peptonoids being administered in small quantities every alternate hour. On the third day, Mellin's food, made with milk, was added, and as the sickness was entirely absent the quantities of nourishment given were increased. For the first three or four days the patient's condition remained critical, the pulse being very small and weak. Otherwise the conditions were favourable. The temperature kept normal, and there was an entire absence of any abdominal symptoms. On the third day the bowels acted of themselves, but I was inclined to think that this was due to the rectal feeding, and that what came away, though dark in colour, like what was syphoned out of the stomach at the time of the operation, was the debris of the suppositories. By the end of the first week my anxieties were lessened, and the patient was in every way stronger. The pulse, too, became better, and there was an entire absence of any gastric uneasiness. On the tenth day the stitches were taken out of the abdominal wound, which was found united throughoutits whole length. The diet was gradually made more liberal, both as to quantity and variety, so that in the third week she was having white fish, minced chicken, peptonised milk, ordinary tea, and bread-and-butter. With the aid of enemata the bowels acted regularly, and on some days of their own accord. Sleep had returned, and she expressed herself as feeling better and more comfortable than she had done for months, having entirely lost the sense of weight in the stomach, with constant desire to vomit, that she had suffered from for so long. To some extent she was losing her emaciated look, and was putting on flesh. Three weeks after the operation I yielded to her oftenrepeated request to get up, and she sat up daily. On one ot these days she walked about the room, and stood between an open window and the door, with the result that she took an attack of bronchial catarrh, "with some congestion of her right lung. Notwithstanding everything that was done, the pulmonary conditions never yielded, and she died after three days' illness, just four weeks after the operation.

Permission was given to examine only the abdomen and the parts involved in the operation. This was done for me by Dr. Henry Rutherfurd, to whom I am indebted for the following particulars. On opening the abdomen, a coil of small in testine was found attached along the greater curvature of the stomach from a point about an inch and a half to a point about five inches and a quarter from the pylorus, but in the last inch and a half or thereabouts, the union was extremely intimate, and the surface of the intestine passed insensibly by the medium of strong adhesions with polished surface into that of the stomach. The centre of this (operator's) adhesion was about four inches and three-quarters from the pylorus, and it was quite is wice as far from the lesser as from the greater curvature, while it is quite free from the region involved in the tumour. This latter formed a somewhat sausage-shaped swelling extending from the pylorus to the extent of three inches and a quarter. Examined from within, the growth was found to involve the whole periphery of the pylorus within the distance mentioned, so that the lumen of the passage was practically obliterated. Microscopic examination showed the thickened walls of the pylorus to be infiltrated with epithelial cells in a state of colloid de generation. No large glands were found obviously involved, but in the omentum in the vicinity of the growth were abundant minute nodules with a characteristic, tense, glistening appearance. The aperture between the stomach and the intestine was oval, with smooth regular borders, and barely admitted the index finger. The bone plates had quite dis appeared, but the silk sutures of apposition seemed quite unaltered. Examination of the thoracic viscera through the diaphragm showed the lungs crepitant and free from any consolidation, but the heart was very soft and flabby and its walls extremely thin.

Such is a brief outline of these two cases, and I have put them on record as they bear on the still unsettled question of the proper surgical treatment of carcinoma of the pylorus. Ever since 1881, when Wölfler of Vienna first performed gastro-enterostomy as a substitute for pylorectomy in a case unsuitable for that procedure, the opinion has been gaining ground that perhaps, after all, the former operation is the more applicable of the two in cases of malignant disease of the outlet of the stomach. There can be no doubt that it is more quickly performed, especially with the improved methods of operating, and that its immediate effects are not so serious. These reasons alone give it a wider range of applicability, in that it allows a greater number of cases being submitted to it. Instances of extreme emaciation and bodily weakness, such as the last of the cases described ahove, may be operated on with a fair prospect of success, and with great relief to symptoms both distressing and dangerous to life. There can be no doubt that it is the operation where the pylorus is occluded by cicatricial tissue the result of ulceration, and is decidedly preferable to pylorectomy or Loreta's method. I am not prepared to say that it will give as great a prolongation to life as a successful case of excision of the pylorus, where the disease has been limited, and there has been no glandular implication; but so few cases of this kind occur that some time must elapse before statistics on this point can be forthcoming. At present I know of none, for those of v. Hacker, Saltzmann, and Rockwitz throw no light on this aspect of the question. From the experience gained in the above two cases of gastroenterostomy I would offer the following remarks :-l. That the routine practice of washing out the stomach preparatory to operation is not absolutely essential, and may be omitted in cases of great weakness and nervousness. Where, however, it has formed part of the treatment of that dilatation of the stomach which so invariably accompanies pyloric obstruction, it may be advantageously employed. If omitted, the stomach should be syphoned out at the time the incision is made into it. With care there need be no more risk of the contents entering the abdomen than in the tapping of an ovarian cyst. 2. The line of incision for opening the abdomen is as well made in the linea alba as anywhere else, and I think it should be placed much lower then is usually advised. In both my cases I commenced between the ensiform cartilage and the umbilicus, and I 
found, especially in the last case, that I was nuch too high. No doubt in this case the stomach was very much dilated, reaching down almost to Poupart's ligament, and forming a complete covering over all the collapsed intestines; but this condition has to be reckoned with in all cases calling for gastro-enterostomy, and a low incision allows of thenecessary manipulations being more conveniently carried out. 3. For compression of the intestine I think Makin's clamps most suitable. They are preferable to the bits of rubber tubing usually advocated, being easily applied and quickly removed. 4. It is not arlvisable that there should be any great searching for a coil of in testine nearest the duodenum. Physiologically, it would seem most correct to get the connexion with the stomach made at as high a point as possible; but probably it is preferable to select a coil of bowel that applies itself easily and conveniently than to have any prolonged search in the abdomen. 5. The plan of carrying the gut round the edge of the omentum and fastening it to the anterior wall of the stomach answered well in both these cases, and gave rise to no kinking of the bowel. It seems preferable to making an artificial opening in the omentum, and less troublesome than turning up that structure along with the transverse colon and uniting the bowel to the posterior surface of the stomach. 6. The use of the bone plates for connecting together the stomach and bowel is a great advance on the former method of close sutures, and considerably shortens the operation. The unaltered condition of the silk sutures around the artificial opening, as revealed by the post-mortem examination in my second case, is an argument in favour of adopting Mr. Jessett's suggestion that the plates should be threaded with chromic gut instead of Chinese silk. It bas, too, occurred to me whether we should not go a step further and adopt Dr. Abbey's suggestion, as given in the New York Medical Journal, and employ rings of chromic gut instead of the bone plates. They would remain firmer and unacted on longer, which might be advantageous. It will be remembered that in my first case it was found that the plates in three cases had been almost entirely dissolved, and the loss of their support had to some extent permitted the serous surfaces to fall apart. Anything that will favour the patency of the artificial opening is to be advocated, for the necropsies of cases of gastro-enterostomy fatal some time after have shown that the fistula was contracted by cicatricial and spur formations, and that the avenue of entrance $t$ s the intestine was obstructed. In one case, too, the unaltered silk stitches had allowed food to clog around them and completely blocked the opening. 7 . In the after treatment of cases of gastruenterostomy too much reliance must not be placed on rectal feeding. Food in small quantities should be given early by the mouth. In this way only can the tendency to death from asthenia be successfully combated. The broad support furnished by the bone plates is quite able to withstand any pelistaltic action of the surrounding parts, and there is no risk of the stitches giving way. This was the lesson I learnt from the examination of the parts in my first case, and from what Mr. Jessett writes me I find that he is of the same opinion. The fatal result in my second case also serves as a warning against allowing the patient up too early during convalescence. When the case appeared within a measurable distance of success, and had, su to speak, weathered the storm, I had the disappointment of seeing it wrecked by injudiciousness on my part. 8. Lastly, all these cases of pyloric disease point to the necessity of early physical examination of the abdomen. It should be a rule with physicians to carry this out in all cases of indigestion that do not yield to treatment in a reasonable time. It is only in this way that early recognition of these cases will take place, thus allowing them to be handed over to the care of the surgeon when they are in a condition to benefit by operative measures, and obtain full advantage of those remedial measures that modern surgery has to offer.

Glasgow.

SCARlatina at Clonmel.-A serious outbreak of scarlatina is reported from Clonmel. The Local Government Board have Jately called attention to defective sewerage and want of pure water, and the Corporation bave adopted a costly waterworks scheme. The corporation have ordered the public schools to be closed for the present.

\section{ON AMENORRH(EA WITH MENTAL DEPRES-} SION, AND FROM MENTAL SHOCK. ${ }^{1}$

By G. ERNEST HERMAN, M.B. LoND , F.R.C.P., obstetric PHYSICIAN TO THE IONDON HOSPITAL, ETC.

Mental Depression is given in text-books as one of the causes of amenorrhoca. Some degree of mental depression is a common effect of ill health, but such mental depression as may be present from anemia and wasting diseases is not sufficient per se to cause amenorrhoa. People in good health are not exempt from anxiety and unhappiness; but mere depression of spirits in a person in good physical health is not capable of causing amenorrhoa. The kind of mental depression which causes amenorrhcea is not simply a "cast of thought"-it is a manifestation of a state of health which affects the whole body : digestion, circulation, and nutrition, as well as the reproductive and nervous systems. I have heard of a mental shock permanently stoppin $g$ menstrua. tion, but disturbing health in no other way. I have never seen any such case till long afterwards, when the details of $a$ passing disturbance of health niay have been forgotten. In all such cases that I have seen at the time there have been other symptoms besides amenorrhcea. No text-book on diseases of women that I know of describes the clinical features of cases of amenorrhoea with mental depression, and in many of the books such information as is given is followed by details as to local treatment for the purpose of producing menstruation. The view that the absence of menstruation nay be the cause of mental symptoms, and that the re-establishment of the flow should be made a principal end of treatment, is as old as Hippocrates, and would thus appear to still find favour. This kind of illness is a quite definite form, the subjects of which often come to an obstetric physician because the illness is accompanied with amenorrhoea, and they or their friends think that the absence of menstruation is the cause of the illness. The cases I am about to speak of may be familiar to many; but the scanty account of them in the ordinary text-books of the diseases of women is my excuse for presuming to say a little about them. The chief complaint is of great depression of spirits. The patient has no delusions or suicidal tendencies, conducts berself rationally, and is not incapacitated for the business of life. With the depression of spirits there is some degree of mental confusion and of incapacity for mental effort. It is not the irritability of neurasthenia, but rather dulness and apathy. There are loss of appetite and constipation; there is some degree of wasting; the hands and feet are cold and damp; there are no physical signs of gross organic disease anywhere. The patients are not anæmic; there are no symptoms of uterine or pelvic aisease beyond the amenorrhoea. The symptoms are, in fact, those of melancholia in a slight degree, and there would be no object in calling the disease by any other name than slight melancholia were it not that the word "melancholia" brings with it the stigma of insanity. These slight cases do not, if they are properly treated, become insane. On the contrary, the condition is curable. As a rule, there is not a clear family history of insanity; but this, I imagine, is because patients with a strong tendency to insanity would become actually insane under the influence of conditions such as bring about the slighter condition of deranged health which $I$ now describe. I see no reason for suppo-ing that the suppression of menstruation has any effect in producing the morbid state. I take the suspended menstruation to be one of the symptoms. I shall now relate some characteris tic cases of the kind.

CASE 1 (reported by Mr. W. A. Rudd).-M. B_-, aged thirty-two, was admitted into the London Hospital on May 12th, 1887. The patient is one of thirteen children, of whom six died young. The mother died fifteen years ago from a tumour. The father is now in good health, but ten year's ago he had some mental ailment, which was of such a nature as to keep him away from business and oblige bim to dispose of it. A brother died from fits, from which he had suffered for six or seven years, aged twenty-nine. She has always had a comfortable home; was never very bright; duller than usual lately. She was always of a 